\title{
Proposed Model for Evaluating Information Systems Quality Based on Single Valued Triangular Neutrosophic Numbers
}

\author{
Samah Ibrahim Abdel Aal ${ }^{a}$, Mahmoud M. A. Abd Ellatif ${ }^{b}$, and Mohamed Monir Hassan ${ }^{c}$ \\ ${ }^{a}$ Assistant lecturer, Faculty of Computers and Informatics, Zagazig University, Egypt \\ ${ }^{b}$ Associate prof. University of Jeddah, KSA University of Helwan, Egypt Faculty of Computers \& INF. \\ ${ }^{c}$ Head of Information Systems Department, Faculty of Computers and Informatics, Zagazig University, Egypt
}

Received: 04 August 2017; Accepted: 16 October 2017; Published: 08 January 2018

\begin{abstract}
One of the most important reasons for information systems failure is lack of quality. Information Systems Quality (ISQ) evaluation is important to prevent the lack of quality. ISQ evaluation is one of the most important Multi-Criteria Decision Making (MCDM) problems. The concept of Single Valued Triangular Neutrosophic Numbers (SVTrN-numbers) is a generalization of fuzzy set and intuitionistic fuzzy set that make it is the best fit in representing indeterminacy and uncertainty in MCDM. This paper aims to introduce an ISQ evaluation model based on SVTrN- numbers with introducing two types of evaluating and ranking methods. The results indicated that the proposed model can handle ill-known quantities in evaluating ISQ. Also by analyzing and comparing results of ranking methods, the results indicated that each method has its own advantage that make the proposed model introduces more than one option for evaluating and ranking ISQ.
\end{abstract}

Index Terms: Information Systems (IS), Information Systems Quality (ISQ), International Standards for Organization (ISO), Multi-Criteria Decision Making (MCDM), Single Valued Triangular Neutrosophic Number (SVTrN).

(C) 2018 Published by MECS Publisher. Selection and/or peer review under responsibility of the Research Association of Modern Education and Computer Science

\section{Introduction}

ISQ evaluation is one of important MCDM problems. The concept of neutrosophic set provides a generalization of fuzzy set and intuitionistic fuzzy set [22, 33]. As [29] pointed out, neutrosophic components are best fit in representing indeterminacy and inconsistent information. In the neutrosophic set, the membership

\footnotetext{
* Corresponding author.

E-mail address: eng_samah2013@yahoo.com,drmmlatif2025@yahoo.com
} 
function independently indicates: Truth-membership-membership degree, false membership-membership degree, and Indeterminacy-membership degree. Neutrosophic set is more powerful in expressing the uncertainty and indeterminate than intuitionistic fuzzy set and fuzzy set. SVTrN-number is a special case of neutrosophic set that can handle ill-known quantity very difficult problem in MCDM. This research aims to introduce an ISQ evaluation model based on SVTrN-numbers with introducing two types of evaluation and ranking methods. The results indicated that the proposed model can handle ill- known quantities in evaluating ISQ. Also by analyzing and comparing results of ranking methods, the results indicated that each method has its own advantage that make the proposed model introduces more than one option for evaluating and ranking ISQ. This paper is organized as the follows: the first section presents the introduction for this work; the second section introduces information systems quality evaluation criteria; the third section provides basic definitions; the fourth section: introduces the proposed model for evaluating ISQ; the fifth section gives conclusion and future work; the final section provides references.

\section{Related Work}

In a MCDM problem, the ranking of alternatives with neutrosophic numbers is many difficult because neutrosophic numbers are not ranked by ordinary methods as real numbers. However it is possible with score functions, aggregation operators, distance measures, and so on. As [15] stated there are several ranking methods. However, there is no unique best approach exists. In [18] proposed a ranking method to order triangular intuitionistic fuzzy numbers by accepting a statistical viewpoint and interpreting each IFN as ensemble of ordinary fuzzy numbers. Ye [28] presented the notations of simplified neutrosophic sets and gave the operational laws of simplified neutrosophic sets. Then, he introduced some aggregation operators and developed ranking method. In [5] developed a ranking method for trapezoidal intuitionistic fuzzy numbers and taking sum of value and ambiguity index. In [20] introduced the concept of multi-valued neutrosophic set with the operations. Then, they gave two multi-valued neutrosophic power aggregation operators and applied to multi-criteria group decision-making problems. Li [13] provides ratio ranking method for TIFNs and cut sets of intuitionistic trapezoidal fuzzy numbers. Li et al [14] introduced a ranking method of triangular intuitionistic fuzzy numbers that depend on value index and ambiguity index for solving multi criteria decision-making problems. Liang et al [15] proposed a ranking method based on the expected values, the score function and the accuracy function of triangular intuitionistic fuzzy number. In [27] [30] introduced score values operators for rankings alternatives. Ye [26] proposed the concept of expected value method for intuitionistic trapezoidal fuzzy and applied it to multi-criteria decision-making problems. Deli and Şubaş [6] adapted and generalized Li et al [14] method to SVN-numbers and the results show that this method is effective and feasible. Prakash et al [21] introduced a ranking method for both trapezoidal intuitionistic fuzzy numbers and triangular intuitionistic fuzzy numbers using the centroid concept and showed the proposed method is flexible and effective.

\section{Information Systems Quality Evaluation Criteria}

Evaluating ISQ is one of the most important MCDM problems. For evaluating ISQ, it is important to use widely accepted quality models to identify ISQ criteria and representing how quality criteria are related to each. System and software quality model provide a good tool to evaluate the quality of system and software product [24] that can support ISQ. System and software quality models include: ISO/IEC 9126 for software quality, ISO/IEC 25010 has been extended to include computer systems, and quality in use from a system perspective, and ISO/IEC 25012 describes the data quality model [11] that can support creators of large and small scale databases. ISO/IEC 25030 focuses on specifying quality requirements [10]. According to [17] [8], the use of models is an acceptable means can support system and software products.. Each of these quality models differ on terminology and quality characteristics they define. The most widely adopted one is the ISO/IEC series of quality standards, especially the ISO 9126 and ISO25010 [19]. ISO/IEC9126 contains two-part quality model 
for software quality. The first part introduced the internal and external quality model that identified six quality characteristics of software quality (Functionality, Reliability, Usability, Efficiency, Maintainability and Portability) [9]. The second part introduced the quality in use model that identified four characteristics (Effectiveness, Productivity, Safety, and Satisfaction). As [1] pointed out, ISO has recognized a need for further enhancement of ISO 9126. ISO/IEC 25010 defines two quality models: product quality model and quality in use model [12]. The product quality model consists of eight characteristics (functional suitability, performance efficiency, compatibility, usability, reliability, security, maintainability and portability). The quality in use model consists of five characteristics (effectiveness, efficiency, satisfaction, freedom from risk, and context coverage).

\section{Basic Definitions}

Fuzzy theory is an important and interesting research topic in decision-making theory and can handle inexact and vague information [31]. However, fuzzy set is characterized only by its membership function between 0 and 1, but not a non-membership function [4]. To overcome the insufficient of fuzzy set, [3] extended fuzzy set and introduced intuitionistic fuzzy set by adding an additional non-membership degree, which may express more flexible information as compared with the fuzzy set. Intuitionistic fuzzy set can be defined as the follows:

Definition 4.1. According to [2], let $\mathrm{E}$ be a universe. An intuitionistic fuzzy set $\mathrm{K}$ over $\mathrm{E}$ is defined by: $\mathrm{K}=$ $\left\{\left\langle x, \mu_{k}(x), \gamma_{k}(x)>: x \in E\right\}\right.$ where $\mu_{k}: E \rightarrow[0,1]$ and $\gamma_{k}: E \rightarrow[0,1]$ such that $0 \leq, \mu_{k}(x)+\gamma_{k}(x) \geq 1$ for any $x \in$ E. For each $x \in E$, the values, $\mu_{k}(x)$ and $\gamma_{k}(x)$ are degree of membership function and non-membership function of $\mathrm{x}$, respectively.

The concept of neutrosophic set came from a philosophical point of view to express indeterminate and inconsistent information [23]. The concept of neutrosophic set introduced a generalization of fuzzy set and intuitionistic fuzzy set [22,32] and it is characterized by its membership function and non-membership function between 0 and 1 . In the neutrosophic set, the membership function independently indicates: Truthmembership-membership degree, false membership-membership degree, and indeterminacy-membership degree. Neutrosophic set can be defined as the follows:

Definition 4.2. According to [23], let $\mathrm{E}$ be a universe. A neutrosophic sets A over $\mathrm{E}$ is defined by:

$A=\left\{\left\langle x,\left(T_{A}(x), I_{A}(x), F_{A}(x)\right)\right\rangle: x \in E\right\}$ where $T_{A}(x), I_{A}(x)$, and $F_{A}(x)$ are called truth-membership function, indeterminacy-membership function and falsity membership function, respectively. They are respectively defined by $\left.\mathrm{T}_{\mathrm{A}}: \mathrm{E} \rightarrow\right]^{-0} 0,1^{+}\left[, \mathrm{I}_{\mathrm{A}}: \mathrm{E} \rightarrow\right]^{-0} 0,1^{+}\left[, \mathrm{F}_{\mathrm{A}}: \mathrm{E} \rightarrow\right]^{-0} 0,1^{+}[$

Such that. $0 \leq^{-}\left(T_{A}(x)+I_{A}(x)+F_{A}(x) \geq 3^{+}\right.$

\subsection{Single Valued Triangular Neutrosophic Numbers}

Single valued triangular neutrosophic numbers (SVTrN-numbers) is a special case of neutrosophic set that can handle ill-known quantity very difficult problem in multi-attribute decision making and ranking. SVTrNnumbers is suitable for the expression of incomplete, indeterminate, and inconsistent information in actual applications. Specially, it has been widely applied in many areas [27] such as decision-making, image processing, medical diagnosis, fault diagnosis.

Definition 4.3. According to [6] [25] SVTrN-numbers a can be defined as the follows: let $\bar{a}=((a, b, c)$; $\left.\mathrm{w}_{\overline{\mathrm{a}}}, \mathrm{u}_{\overline{\mathrm{a}}}, \mathrm{y}_{\overline{\mathrm{a}}}\right)$ where is a SVTrN-number whose truth-membership, indeterminacy-membership and falsitymembership functions are respectively defined by:

$$
\mu_{\overline{\mathrm{a}}}(\mathrm{x})=\left\{\left((\mathrm{x}-\mathrm{a}) \mathrm{w}_{\overline{\mathrm{a}}}\right) /(\mathrm{b}-\mathrm{a}) \text { for } \mathrm{a} \leqslant \mathrm{x}<\mathrm{b},\left((\mathrm{c}-\mathrm{x}) \mathrm{w}_{\overline{\mathrm{a}}}\right) /(\mathrm{c}-\mathrm{b}) \text { for } \mathrm{b} \leqslant \mathrm{x} \leqslant \mathrm{c}, 0\right. \text { for otherwise }
$$


$\mathrm{v}_{\overline{\mathrm{a}}}(\mathrm{x})=\left\{\left(\mathrm{b}-\mathrm{x}+\mathrm{u}_{\overline{\mathrm{a}}}(\mathrm{x}-\mathrm{a})\right) /(\mathrm{b}-\mathrm{a})\right.$ for $\mathrm{a} \leqslant \mathrm{x}<\mathrm{b},\left(\mathrm{x}-\mathrm{b}+\mathrm{u}_{\overline{\mathrm{a}}}(\mathrm{c}-\mathrm{x})\right) /(\mathrm{c}-\mathrm{b})$ for $\mathrm{b} \leqslant \mathrm{x} \leqslant \mathrm{c}, 0$ for otherwise

$\lambda_{\overline{\mathrm{a}}}(\mathrm{x})=\left\{\left(\mathrm{b}-\mathrm{x}+\mathrm{y}_{\overline{\mathrm{a}}}(\mathrm{x}-\mathrm{a})\right) /(\mathrm{b}-\mathrm{a})\right.$ for $\mathrm{a} \leq \mathrm{x}<\mathrm{b},\left(\mathrm{x}-\mathrm{b}+\mathrm{y}_{\overline{\mathrm{a}}}(\mathrm{c}-\mathrm{x})\right) /(\mathrm{c}-\mathrm{b})$ for $\mathrm{b} \leq \mathrm{x} \leq \mathrm{c}, 0$ for otherwise

If $\mathrm{a} \geq 0$ and at least $\mathrm{c}>0$, then $\overline{\mathrm{a}}=\left((\mathrm{a}, \mathrm{b}, \mathrm{c}) ; \mathrm{w}_{\overline{\mathrm{a}}}, \mathrm{u}_{\overline{\mathrm{a}}}, \mathrm{y}_{\overline{\mathrm{a}}}\right)$ is called a positive SVTrN-number, denoted by $\overline{\mathrm{a}}>0$. Likewise, If $\mathrm{a} \leq 0$ and at least $\mathrm{c}<0, \overline{\mathrm{a}}=\left((\mathrm{a}, \mathrm{b}, \mathrm{c}) ; \mathrm{w}_{\overline{\mathrm{a}}}, \mathrm{u}_{\overline{\mathrm{a}}}, \mathrm{y}_{\overline{\mathrm{a}}}\right)$ is called a negative $\mathrm{SVTrN}$-number, denoted by $\overline{\mathrm{a}}<0$.

Definition 4.4. According to [25] let $\bar{a}=\left(\left(a_{1}, b_{1}, c_{1}\right) ; w_{\bar{a}}, u_{\bar{a}}, y_{\bar{a}}\right), \bar{e}=\left(\left(a_{2}, b_{2}, c_{2}\right) ; w_{\bar{e}}, u_{\bar{e}}, y_{\bar{e}}\right)$ be two SVTrNnumbers and $\gamma \neq 0$ be any real number, then

$$
\overline{\mathrm{a}}+\overline{\mathrm{e}}=\left(\left(\mathrm{a}_{1}+\mathrm{a}_{2}, \mathrm{~b}_{1}+\mathrm{b}_{2}, \mathrm{c}_{1}+\mathrm{c}_{2}\right) ; \min \left\{\mathrm{w}_{\overline{\mathrm{a}}}, \mathrm{w}_{\overline{\mathrm{e}}}\right\}, \max \left\{\mathrm{u}_{\overline{\mathrm{a}}}, \mathrm{u}_{\overline{\mathrm{e}}}\right\}, \max \left\{\mathrm{y}_{\overline{\mathrm{a}}}, \mathrm{y}_{\overline{\mathrm{e}}}\right\}\right)
$$

$\overline{\mathrm{a}} \overline{\mathrm{e}}=\left\{\left(\left(\mathrm{a}_{1} \mathrm{a}_{2}, \mathrm{~b}_{1} \mathrm{~b}_{2}, \mathrm{c}_{1} \mathrm{c}_{2}\right), \min \left\{\mathrm{w}_{\overline{\mathrm{a}}}, \mathrm{w}_{\overline{\mathrm{e}}}\right\}, \max \left\{\mathrm{u}_{\overline{\mathrm{a}}}, \mathrm{u}_{\overline{\mathrm{e}}}\right\}, \max \left\{\mathrm{y}_{\overline{\mathrm{a}}}, \mathrm{y}_{\overline{\mathrm{e}}}\right\}\right)\right.$ for $\left(\mathrm{c}_{1}>0, \mathrm{c}_{2}>0\right),\left(\left(\mathrm{a}_{1} \mathrm{c}_{2}, \mathrm{~b}_{1} \mathrm{~b}_{2}, \mathrm{c}_{1} \mathrm{a}_{2}\right)\right.$, $\left.\min \left\{\mathrm{w}_{\overline{\mathrm{a}}} \quad, \mathrm{w}_{\overline{\mathrm{e}}}\right\}, \max \left\{\mathrm{u}_{\overline{\mathrm{a}}}, \mathrm{u}_{\overline{\mathrm{e}}}\right\}, \max \left\{\mathrm{y}_{\overline{\mathrm{a}}} \quad, \mathrm{y}_{\overline{\mathrm{e}}}\right\}\right) \quad$ for $\quad\left(\mathrm{c}_{1}<0, \mathrm{c}_{2}>0\right) \quad\left(\left(\mathrm{c}_{1} \quad \mathrm{c}_{2}, \mathrm{~b}_{1} \quad \mathrm{~b}_{2}, \mathrm{a}_{1} \quad \mathrm{a}_{2} \quad\right), \quad \min \right.$ $\left.\left\{\mathrm{w}_{\overline{\mathrm{a}}}, \mathrm{w}_{\overline{\mathrm{e}}}\right\}, \max \left\{\mathrm{u}_{\overline{\mathrm{a}}}, \mathrm{u}_{\overline{\mathrm{e}}}\right\}, \max \left\{\mathrm{y}_{\overline{\mathrm{a}}}, \mathrm{y}_{\overline{\mathrm{e}}}\right\}\right)$ for $\left.\left(\mathrm{c}_{1}<0, \mathrm{c}_{2}<0\right)\right)$

$$
\gamma \bar{a}=\left\{\left(\left(\gamma a_{1}, \gamma b_{1}, \gamma c_{1}\right) ; w_{\bar{a}}, u_{\bar{a}}, y_{\bar{a}}\right) \text { for }(\gamma>0),\left(\left(\gamma c_{1}, \gamma b_{1}, \gamma a_{1}\right) ; w_{\bar{a}}, u_{\bar{a}}, y_{\bar{a}}\right) \text { for } \quad(\gamma<0)\right.
$$

\subsubsection{Concepts of Values and Ambiguities for SVTrN-Numbers}

Concept of cut (or level) sets, values, ambiguities, weighted values and weighted ambiguities of SVTrNnumbers have desired properties and can reflect information on membership degrees and non-membership degrees.

Definition 4.5. As [6] [13] pointed out, let $\bar{a}=\left(\left(a_{1}, b_{1}, c_{1}\right) ; w_{\bar{a}}, u_{\bar{a}}, y_{\bar{a}}\right)$ is an arbitrary SVTrN-number. Then,

1. $\alpha$-cut set of the SVTrN-number a for truth-membership is calculated as:

$$
\left[\mathrm{L}_{\overline{\mathrm{a}}}(\alpha), \mathrm{R}_{\overline{\mathrm{a}}}(\alpha)\right]=\left[\left(\left(\mathrm{w}_{\overline{\mathrm{a}}}-\alpha\right) \mathrm{a}+\alpha \mathrm{b}\right) / \mathrm{w}_{\overline{\mathrm{a}}},\left(\left(\mathrm{w}_{\overline{\mathrm{a}}}-\alpha\right) \mathrm{c}+\alpha \mathrm{b}\right) / \mathrm{w}_{\overline{\mathrm{a}}}\right]
$$

If $f(\alpha)=\alpha$, where $f(\alpha) \in[0,1]$ and $f(\alpha)$ is monotonic and non-decreasing of $\alpha \in\left[0, \mathrm{w}_{\overline{\mathrm{a}}}\right]$, the value and ambiguity of the SVTrN-number à can be calculated as:

$$
\mathrm{V}_{\mu}(\overline{\mathrm{a}})=\left((\mathrm{a}+4 \mathrm{~b}+\mathrm{c})\left(\mathrm{w}_{\overline{\mathrm{a}}}\right)^{2}\right) / 6
$$

$$
\mathrm{A}_{\mu}(\overline{\mathrm{a}})=\left((\mathrm{c}-\mathrm{a})\left(\mathrm{w}_{\overline{\mathrm{a}}}\right)^{2}\right) / 6
$$

2. $\beta$-cut set of the SVTrN-number $\bar{a}$ for indeterminacy membership is calculated as;

$$
\left[\dot{L}_{\bar{a}}(\beta), \hat{R}_{\bar{a}}(\beta)\right]=\left[\left((1-\beta) b+\left(\beta-u_{\bar{a}}\right) a\right) /\left(1-u_{\bar{a}}\right),\left((1-\beta) b+\left(\beta-u_{\bar{a}}\right) c\right) /\left(1-u_{\bar{a}}\right)\right]
$$

If $g(\beta)=1-\beta$, where $g(\beta) \in[0,1]$ and $g(\beta)$ is monotonic and non-increasing of $\beta \in\left[\mathrm{u}_{\bar{a}}, 1\right]$, the value and ambiguity of the SVTrN-number à can be calculated, respectively, as the follows:

$$
\begin{aligned}
& \mathrm{V}_{v}(\overline{\mathrm{a}})=\left((\mathrm{a}+4 \mathrm{~b}+\mathrm{c})\left(1-\mathrm{u}_{\overline{\mathrm{a}}}\right)^{2}\right) / 6 \\
& \mathrm{~A}_{v}(\overline{\mathrm{a}})=\left((\mathrm{c}-\mathrm{a})\left(1-\mathrm{u}_{\overline{\mathrm{a}}}\right)^{2}\right) / 6
\end{aligned}
$$


3. $\quad \gamma$ - cut set of the SVTrN-number a for falsity-membership is calculated as;

$$
\left.\left[\dot{L}_{\bar{a}}^{\prime}(\gamma), \hat{R}_{\bar{a}}^{\prime}(\gamma)\right]=\left[\left((1-\gamma) b+\left(\gamma-y_{\bar{a}}\right) a\right) /\left(1-y_{\bar{a}}\right)\right),\left((1-\gamma) b+\left(\gamma-y_{\bar{a}}\right) c\right) /\left(1-y_{\bar{a}}\right)\right]
$$

If $h(\gamma)=1-\gamma$, where $h(\gamma) \in[0,1]$ and $h(\gamma)$ is monotonic and non-increasing of $\gamma \in\left[\mathrm{y}_{\bar{a}}, 1\right]$, the value and ambiguity of the SVTrN-number $\overline{\mathbf{a}}$, respectively, as;

$$
\begin{aligned}
& \mathrm{V}_{\lambda}(\overline{\mathrm{a}})=\left((\mathrm{a}+4 \mathrm{~b}+\mathrm{c})\left(1-\mathrm{y}_{\overline{\mathrm{a}}}\right)^{2}\right) / 6 \\
& \mathrm{~A}_{\lambda}(\overline{\mathrm{a}})=\left((\mathrm{c}-\mathrm{a})\left(1-\mathrm{y}_{\overline{\mathrm{a}}}\right)^{2}\right) / 6
\end{aligned}
$$

The function $f(\alpha)$ gives different weights to elements at different $\alpha$-cut sets and these cut sets come from values of $\mu_{\overline{\mathrm{a}}}(\mathrm{x})$ which have a considerable amount of uncertainty. Therefore, $\mathrm{V}_{\mu}(\overline{\mathrm{a}})$ can reflect the information on membership degrees. Also, $g(\beta)$ can lessen the contribution of the higher $\beta$-cut sets come from values of $v_{\overline{\mathrm{a}}}$ (x) which have a considerable amount of uncertainty. Therefore, $\mathrm{V}_{v}(\overline{\mathrm{a}})$ can reflect the information on nonmembership degrees. Likewise, $V_{\lambda}(\bar{a})$ can reflect the information on non-membership degrees.

\subsubsection{The Weighted Values and Ambiguities of the SVTrN-numbers}

The weighted values of the SVTrN-numbers can be calculated as follows:

Definition 4.6. According to [6] let $\bar{a}=\left(\left(a_{1}, b_{1}, c_{1}\right) ; w_{\bar{a}}, u_{\bar{a}}, y_{\bar{a}}\right)$ be a $S V T r N$-number. Then, for $\theta \in[0,1]$, the $\theta$ weighted value of the SVTrN-number $\bar{a}$ can be defined as:

$$
\mathrm{V}_{\theta}(\overline{\mathrm{a}})=(\mathrm{a}+4 \mathrm{~b}+\mathrm{c}) / 6\left[\theta \mathrm{w}_{\overline{\mathrm{a}}}^{2}+(1-\theta)\left(1-\mathrm{u}_{\overline{\mathrm{a}}}\right)^{2}+(1-\theta)\left(1-\mathrm{y}_{\overline{\mathrm{a}}}\right)^{2}\right]
$$

The $\theta$ - weighted ambiguity of SVTrN-number à can be defined as:

$$
\mathrm{A}_{\theta}(\overline{\mathrm{a}})=(\mathrm{c}-\mathrm{a}) / 6\left[\theta \mathrm{w}_{\overline{\mathrm{a}}}{ }^{2}+(1-\theta)\left(1-\mathrm{u}_{\overline{\mathrm{a}}}\right)^{2}+(1-\theta)\left(1-\mathrm{y}_{\overline{\mathrm{a}}}\right)^{2}\right]
$$

Definition 4.7. Let $\bar{a}$ and $\bar{e}$ be two SVTrN-numbers and $\theta \in[0,1]$. For weighted values and ambiguities of the SVTrN-numbers $\bar{a}$ and $\overline{\mathrm{e}}$, the ranking order of $\overline{\mathrm{a}}$ and $\overline{\mathrm{e}}$ can be defined as;

(1) If $\mathrm{V}_{\theta}(\overline{\mathrm{a}})>\mathrm{V}_{\theta}(\overline{\mathrm{e}})$, then $\overline{\mathrm{a}}$ is bigger than $\overline{\mathrm{e}}$

(2) If $V_{\theta}(\bar{a})<V_{\theta}(\bar{e})$, then $\bar{a}$ is smaller than $\overline{\mathrm{e}}$

(3) If $\mathrm{V}_{\theta}(\overline{\mathrm{a}})=\mathrm{V}_{\theta}(\overline{\mathrm{e}})$, then

(i) If $\mathrm{A}_{\theta}(\overline{\mathrm{a}})=\mathrm{A}_{\theta}(\overline{\mathrm{e}})$, then then $\overline{\mathrm{a}}$ is equal to $\overline{\mathrm{e}}$

(ii) If $\mathrm{A}_{\theta}(\overline{\mathrm{a}})>\mathrm{A}_{\theta}(\overline{\mathrm{e}})$, then $\overline{\mathrm{a}}$ is bigger than $\overline{\mathrm{e}}$

(iii) If $\mathrm{A}_{\theta}(\overline{\mathrm{a}})<\mathrm{A}_{\theta}(\overline{\mathrm{e}})$, then $\overline{\mathrm{a}}$ is smaller than $\overline{\mathrm{e}}$

\subsubsection{Score and Accuracy Based Method for SVTrN numbers}

According to [6] if $\mathrm{b}=\mathrm{c}$ then the Single-Valued Trapezoidal Neutrosophic Number (SVTN number) is treated as a SVTrN-number. Therefore, the method that introduced by [7] [16] can be adapted to give scores to SVTrN numbers as the follows: 
Definition 4.8. Let $\overline{\mathrm{I}}=\left((\mathrm{a}, \mathrm{b}, \mathrm{c}, \mathrm{d}) ; \mathrm{w}_{\overline{\mathrm{I}}}, \mathrm{u}_{\overline{\mathrm{I}}}, \mathrm{y}_{\overline{\mathrm{I}}}\right)$ be a SVTN number, as [7] [16] pointed out, the score function of $\overline{\mathrm{I}}$ can be defined as:

$$
\mathrm{S}(\overline{\mathrm{I}})=1 / 16\left[(\mathrm{a}+\mathrm{b}+\mathrm{c}+\mathrm{d})\left(2+\mathrm{w}_{\overline{\mathrm{I}}}-\mathrm{u}_{\overline{\mathrm{I}}}-\mathrm{y}_{\overline{\mathrm{I}}}\right)\right]
$$

And the accuracy function can be defined as:

$$
\left.\mathrm{h}(\overline{\mathrm{I}})=1 / 16[(\mathrm{a}+\mathrm{b}+\mathrm{c}+\mathrm{d}))\left(2+\mathrm{w}_{\overline{\mathrm{I}}}-\mathrm{u}_{\overline{\mathrm{I}}}+\mathrm{y}_{\overline{\mathrm{I}}}\right)\right]
$$

If $c=b$, then the score function and the accuracy function of $\bar{I}$ can be defined as:

$$
\begin{aligned}
& S(\bar{I})=1 / 16\left[(a+2 b+d)\left(2+w_{\bar{I}}-u_{\bar{I}}-y_{\bar{I}}\right)\right] \\
& h(\bar{I})=1 / 16\left[(a+2 b+d)\left(2+w_{\bar{I}}-u_{\bar{I}}+y_{\bar{I}}\right)\right]
\end{aligned}
$$

And the SVTN number is treated as a SVTrN-number. Consequently, Definition 4.9. Let $\bar{a}=\left(\left(a_{1}, b_{1}, c_{1}\right)\right.$; $\left.\mathrm{W}_{\overline{\mathrm{a}}}, \mathrm{u}_{\overline{\mathrm{a}}}, \mathrm{y}_{\overline{\mathrm{a}}}\right)$ be a SVTrN-number, the score function and accuracy function of $\overline{\mathrm{a}}$ can be defined, respectively, as the follows:

$$
\begin{aligned}
& S(\bar{a})=1 / 16\left[(a+2 b+c)\left(2+w_{\bar{a}}-u_{\bar{a}}-y_{\bar{a}}\right)\right] \\
& h(\bar{a})=1 / 16\left[(a+2 b+c)\left(2+w_{\bar{a}}-u_{\bar{a}}+y_{\bar{a}}\right)\right]
\end{aligned}
$$

Definition 4.10. Let $\overline{\mathrm{a}}=\left(\left(\mathrm{a}_{1}, \mathrm{~b}_{1}, \mathrm{c}_{1}\right)\right.$; $\left.\mathrm{w}_{\overline{\mathrm{a}}}, \mathrm{u}_{\overline{\mathrm{a}}}, \mathrm{y}_{\overline{\mathrm{a}}}\right), \overline{\mathrm{e}}=\left(\left(\mathrm{a}_{2}, \mathrm{~b}_{2}, \mathrm{c}_{2}\right) ; \mathrm{w}_{\overline{\mathrm{e}}}, \mathrm{u}_{\overline{\mathrm{e}}}, \mathrm{y}_{\overline{\mathrm{e}}}\right)$ be two SVTrN-numbers. The comparison method for $\bar{a}$ and $\bar{e}$ can defined as:
(1) If $\mathrm{S}(\overline{\mathrm{a}})<\mathrm{S}(\overline{\mathrm{e}})$, then $\overline{\mathrm{a}}<\overline{\mathrm{e}}$
(2) If $\mathrm{S}(\overline{\mathrm{a}})>\mathrm{S}(\overline{\mathrm{e}})$, then $\overline{\mathrm{a}}>\overline{\mathrm{e}}$
(3) If $S(\bar{a})=S(\bar{e})$, then
(i) If $\mathrm{h}(\overline{\mathrm{a}})<\mathrm{h}(\overline{\mathrm{e}})$, then $\overline{\mathrm{a}}<\overline{\mathrm{e}}$
(ii) If $\mathrm{h}(\overline{\mathrm{a}})>\mathrm{h}(\overline{\mathrm{e}})$, then $\overline{\mathrm{a}}>\overline{\mathrm{e}}$
(iii) If $\mathrm{h}(\overline{\mathrm{a}})=\mathrm{h}(\overline{\mathrm{e}})$, then $\overline{\mathrm{a}}=\overline{\mathrm{e}}$

\section{The Proposed Model for Evaluating Information Systems Quality}

The proposed model aims to evaluate ISQ by making use of SVTrN-numbers to handle uncertainty in expressing human knowledge as well as provide two ranking methods to give more than one option for evaluating and ranking ISQ. The proposed model consists of three phases as the follows:

Phase I: Construct the SVTrN-Multi-Criteria Decision Matrix of Decision Maker

Let $\mathrm{Q}=\left(\mathrm{q}_{1}, \mathrm{q}_{2} \ldots \mathrm{q}_{\mathrm{n}}\right)$ a set of information systems. $\mathrm{C}=\left(\mathrm{c}_{1}, \mathrm{c}_{2} \ldots \mathrm{c}_{\mathrm{m}}\right)$ be ISQ criteria, and let $\left[\mathrm{A}_{\mathrm{ij}}\right]=\left(\left(\mathrm{a}_{\mathrm{ij}}, \mathrm{b}_{\mathrm{ij}}, \mathrm{c}_{\mathrm{ij}}\right)\right.$; $\left.\mathrm{w}_{\overline{\mathrm{a} i j}}, \mathrm{u}_{\overline{\mathrm{a} i j}}, \mathrm{y}_{\overline{\mathrm{aij}}}\right)\left(\mathrm{i} \in \mathrm{I}_{\mathrm{m}}\right.$ for ISQ criteria, $\mathrm{j} \in \mathrm{I}_{\mathrm{n}}$ information systems) be a SVTrN-number. Then decision matrix can be identified as the follows: 


$$
\left[\mathrm{A}_{\mathrm{ij}}\right]_{\mathrm{m} \cdot \mathrm{n}}=\left(\begin{array}{cccc}
A_{11} & A_{12} & \cdots & A_{1 n} \\
A_{21} & A_{22} & \cdots & A_{2 n} \\
\vdots & & \ddots & \vdots \\
A_{m 1} & A_{m 2} & \cdots & A_{m n}
\end{array}\right)
$$

Phase II: Calculate the Comprehensive Values

At the first, Compute the normalized decision-making matrix $\mathrm{R}=\left[\mathrm{r}_{\mathrm{ij}}\right]_{\mathrm{m}^{*} \mathrm{n}}$ and compute $\mathrm{U}=\left[\mathrm{u}_{\mathrm{ij}}\right]_{\mathrm{m}^{* \mathrm{n}}}$ as the follows:

- Compute the normalized decision-making matrix $\mathrm{R}=\left[\mathrm{r}_{\mathrm{ij}}\right]_{\mathrm{m}{ }^{*} \mathrm{n}}$ where

$\mathrm{R}_{\mathrm{ij}}=\left(\left(\mathrm{a}_{\mathrm{ij}} / \mathrm{a}^{+}, \mathrm{b}_{\mathrm{ijj}} / \overline{\mathrm{a}}^{+}, \mathrm{c}_{\mathrm{ij}} / \overline{\mathrm{a}}^{+}\right) ; \mathrm{w}_{\overline{\mathrm{a} i j}}, \mathrm{u}_{\overline{\mathrm{a}} \mathrm{ij}}, \mathrm{y}_{\overline{\mathrm{aij}}}\right)$

Such that $\bar{a}+=\max \left\{c_{i j} . \quad i \in I_{m}, j \in I_{n}\right\}$

- Compute $U=\left[u_{i j}\right]_{m{ }^{*} n}$ of $R$. Where, $u_{i j=} \omega_{i} r_{i j}\left(i \in I_{m}\right.$ for ISQ criteria, $j \in I_{n}$ information systems),

$\omega=\left(\omega_{1}, \omega_{2} \ldots \omega_{\mathrm{m}}\right)$ be the weight vector of ISQ criteria, where $\omega_{\mathrm{i}} \in[0,1], \mathrm{i} \in \mathrm{I}_{\mathrm{m}}, \sum_{\mathrm{i}=1}^{\mathrm{m}} \omega_{\mathrm{i}}=1$

Then, calculate the comprehensive values $S_{j}$ as:

$\mathrm{S}_{\mathrm{j}}=\sum_{\mathrm{i}=1}^{m} \mathrm{u}_{\mathrm{ij}}=\left(\left(\sum_{\mathrm{i}=1}^{m} \omega_{\mathrm{i}} \mathrm{r}_{\mathrm{ij}}, \sum_{\mathrm{i}=1}^{m} \omega_{\mathrm{i}} \mathrm{r}_{\mathrm{ij}}, \sum_{\mathrm{i}=1}^{m} \omega_{\mathrm{i}} \mathrm{r}_{\mathrm{ij}}\right) ; \max \mathrm{w}_{\overline{\mathrm{a} i \mathrm{j}}}, \min \mathrm{u}_{\overline{\mathrm{a} i j}}, \min \mathrm{y}_{\overline{a i j}}\right) \quad\left(\mathrm{j} \in \mathrm{I}_{\mathrm{n}}\right)$

Phase III: Evaluate and Rank the Quality of IS

This phase aims to introduce two evaluating and ranking methods: (1) - weighted value and ambiguity based method, (2) - score and accuracy based method, to give more than one option for evaluating and ranking ISQ.

(1) Weighted value and ambiguity method

Firstly, calculate the value of truth-membership-membership degree, and indeterminacy-membership, and falsity-membership degree for each comprehensive value based on “Eq. (7)" "Eq. (9)"and "Eq. (11)", respectively, as the follows:

$$
\begin{aligned}
& \mathrm{V}_{\mu}\left(\mathrm{S}_{\mathrm{j}}\right)=\left((\mathrm{a}+4 \mathrm{~b}+\mathrm{c})\left(\mathrm{w}_{\mathrm{sj}}\right)^{2}\right) / 6 \\
& \mathrm{~V}_{v}\left(\mathrm{~S}_{\mathrm{j}}\right)=\left((\mathrm{a}+4 \mathrm{~b}+\mathrm{c})\left(1-\mathrm{u}_{\mathrm{sj}}\right)^{2}\right) / 6 \\
& \mathrm{~V}_{\lambda}\left(\mathrm{S}_{\mathrm{j}}\right)=\left((\mathrm{a}+4 \mathrm{~b}+\mathrm{c})\left(1-\mathrm{y}_{\mathrm{sj}}\right)^{2}\right) / 6
\end{aligned}
$$

And, calculate the ambiguity of truth-membership-membership degree, and indeterminacy-membership, and falsity-membership degree for each comprehensive value based on "Eq. (8)" "Eq. (10)"and "Eq. (12)", respectively, as the follows:

$$
\begin{aligned}
& \mathrm{A}_{\mu}\left(\mathrm{S}_{\mathrm{j}}\right)=\left((\mathrm{c}-\mathrm{a})\left(\mathrm{w}_{\mathrm{sj}}\right)^{2}\right) / 6 \\
& \mathrm{~A}_{v}\left(\mathrm{~S}_{\mathrm{j}}\right)=\left((\mathrm{c}-\mathrm{a})\left(1-\mathrm{u}_{\mathrm{sj}}\right)^{2}\right) / 6
\end{aligned}
$$




$$
\mathrm{A}_{\lambda}\left(\mathrm{S}_{\mathrm{j}}\right)=\left((\mathrm{c}-\mathrm{a})\left(1-\mathrm{y}_{\mathrm{sj}}\right)^{2}\right) / 6
$$

Secondly, calculate the weighted values ( $\theta$-weighted value) for each alternative as the follows:

From "Eq. (13)" "Eq. (22)" "Eq. (23)" and "Eq. (24)" the $\theta$-weighted value of each comprehensive value $S_{j}$ is defined as:

$$
\mathrm{V}_{\theta}\left(\mathrm{S}_{\mathrm{j}}\right)=\mathrm{V}_{\mu}\left(\mathrm{S}_{\mathrm{j}}\right) \theta+\mathrm{V}_{v}\left(\mathrm{~S}_{\mathrm{j}}\right)(1-\theta)+\mathrm{V}_{\lambda}\left(\mathrm{S}_{\mathrm{j}}\right)(1-\theta)
$$

From "Eq. (14)" "Eq. (25)" "Eq. (26)" and "Eq. (27)" The $\theta$ - weighted ambiguity of a comprehensive value $\mathrm{S}_{\mathrm{j}}$ can be defined as:

$$
\begin{aligned}
& \mathrm{A}_{\theta}\left(\mathrm{S}_{\mathrm{j}}\right)=(\mathrm{c}-\mathrm{a}) / 6\left[\theta \mathrm{w}_{\mathrm{j}}{ }^{2}+(1-\theta)\left(1-\mathrm{u}_{\mathrm{sj}}\right)^{2}+(1-\theta)\left(1-\mathrm{y}_{\mathrm{sj}}\right)^{2}\right] \\
& =\mathrm{A}_{\mu}\left(\mathrm{S}_{\mathrm{j}}\right) \theta+\mathrm{A}_{v}\left(\mathrm{~S}_{\mathrm{j}}\right)(1-\theta)+\mathrm{A}_{\lambda}\left(\mathrm{S}_{\mathrm{j}}\right)(1-\theta)
\end{aligned}
$$

Thirdly, represent the weighted values graphically for evaluating and ranking the quality of IS.

(2) Score and Accuracy Based Method

For evaluating ISQ Score and Accuracy can be calculated as the follows:

(i) Calculate the score function and accuracy based "Eq. (19)" and "Eq. (20)".

(ii) Compare the results based on definition 10 for evaluating and ranking ISQ.

\subsection{Case study}

An IS evaluation committee wants to evaluate quality of three IS centers at three universities according eight quality criteria based ISO/IEC 25010: Functionality, reliability, usability, efficiency, maintainability, portability, security, and compatibility. The weight vector of the eight quality criteria is $\omega=$ $(.25, .25, .30, .20, .25, .20, .20$, and .15). The linguistic values to rate the importance of the alternatives is shown in the following table:

Table 1. Linguistic Values to Rate the Importance of the Alternatives

\begin{tabular}{cc}
\hline Linguistic terms & Linguistic values \\
\hline Low & $((4.6 ; 5.5 ; 8.6) ; 0.4 ; 0.7 ; 0.2)$ \\
Not low & $((4.7 ; 6.9 ; 8.5) ; 0.7 ; 0.2 ; 0.6)$ \\
Very low & $((6.2 ; 7.6 ; 8.2) ; 0.4 ; 0.1 ; 0.3)$ \\
Completely low & $((7.1 ; 7.7 ; 8.3) ; 0.5 ; 0.2 ; 0.4)$ \\
More or less low & $((5.8 ; 6.9 ; 8.5) ; 0.6 ; 0.2 ; 0.3)$ \\
Fairly low & $((5.5 ; 6.2 ; 7.3) ; 0.8 ; 0.1 ; 0.2)$ \\
Essentially low & $((5.3 ; 6.7 ; 9.9) ; 0.3 ; 0.5 ; 0.2)$ \\
Neither low nor high & $((6.2 ; 8.9 ; 9.1) ; 0.6 ; 0.3 ; 0.5)$ \\
High & $((6.2 ; 8.9 ; 9.1) ; 0.6 ; 0.3 ; 0.5)$ \\
Not high & $((4.4 ; 5.9 ; 7.2) ; 0.7 ; 0.2 ; 0.3)$ \\
Very high & $((6.6 ; 8.8 ; 10) ; 0.6 ; 0.2 ; 0.2)$ \\
Completely high & $((6.3 ; 7.5 ; 8.9) ; 0.7 ; 0.4 ; 0.6)$ \\
More or less high & $((5.3 ; 7.3 ; 8.7) ; 0.7 ; 0.2 ; 0.8)$ \\
Fairly high & $((6.5 ; 6.9 ; 8.5) ; 0.6 ; 0.8 ; 0.1)$ \\
Essentially high & $((7.5 ; 7.9 ; 8.5) ; 0.8 ; 0.5 ; 0.4)$ \\
\hline
\end{tabular}


For evaluating and ranking the quality of the three IS based on the proposed model, the SVTrN-numbers is applied with introducing the weighted value and ambiguity based method and the score and accuracy based method as the follows:

Phase I: Construct the SVTrN-Multi-Criteria Decision Matrix of Decision Maker

Let $\mathrm{Q}=\left(\mathrm{q}_{1}, \mathrm{q}_{2}, \mathrm{q}_{3}\right)$ be a set of the three IS. $\mathrm{C}=\left(\mathrm{c}_{1}, \mathrm{c}_{2}, \mathrm{c}_{3}, \mathrm{c}_{4}, \mathrm{c}_{5}, \mathrm{c}_{6}, \mathrm{c}_{7}, \mathrm{c}_{8}\right)$ be ISQ criteria: functionality $\mathrm{c}_{1}$, reliability $c_{2}$, usability $c_{3}$, efficiency $c_{4}$, maintainability $c_{5}$, portability $c_{6}$, security $c_{7}$, compatibility $c_{8}$. Let $A=$ $\left[\mathrm{A}_{\mathrm{ijj}}\right]_{8 * 3}=\left(\left(\mathrm{a}_{\mathrm{ijj}}, \mathrm{b}_{\mathrm{ij}}, \mathrm{c}_{\mathrm{ij}}\right) ; \mathrm{w}_{\overline{\mathrm{a}} \mathrm{ij}}, \mathrm{u}_{\overline{\mathrm{a}} \mathrm{ij}}, \mathrm{y}_{\overline{\mathrm{a} i j}}\right)\left(\mathrm{i} \in \mathrm{I}_{8}\right.$ for ISQ criteria, $\mathrm{j} \in \mathrm{I}_{3}$ the three information systems $)$ be a SVTrNnumbers. Then

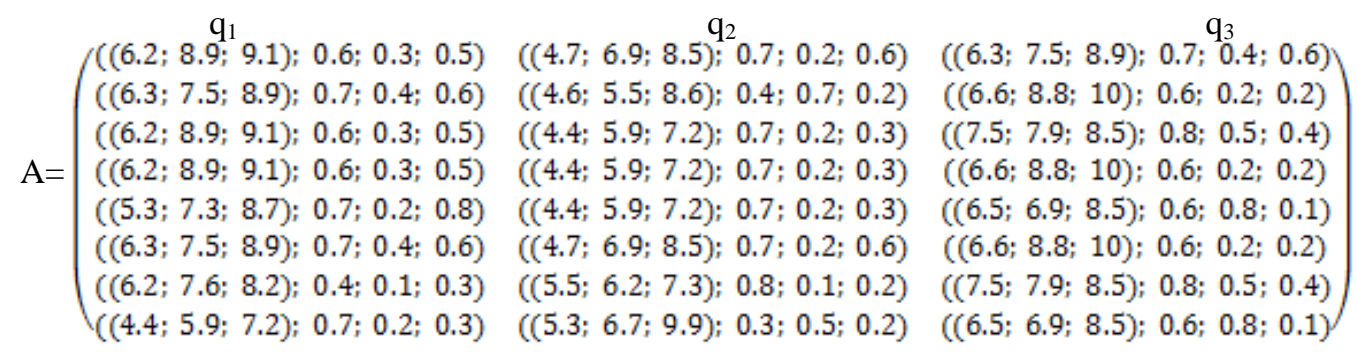

Phase II: Calculate the Comprehensive Values

Before calculating the comprehensive values, Compute the normalized decision-making matrix $\mathrm{R}=\left[\mathrm{r}_{\mathrm{ij}}\right]_{8 * 3}$ and compute $\mathrm{U}=\left[\mathrm{u}_{\mathrm{ij}}\right]_{8 * 3}$ as the follows:

$$
\mathrm{R}=\left(\begin{array}{cccc}
((.62 ; .89 ; .91) ; 0.6 ; 0.3 ; 0.5) & ((.47 ; .69 ; .85) ; 0.7 ; 0.2 ; 0.6) & ((.63 ; .75 ; .89) ; 0.7 ; 0.4 ; 0.6) \\
((.63 ; .75 ; .89) ; 0.7 ; 0.4 ; 0.6) & ((.46 ; .55 ; .86) ; 0.4 ; 0.7 ; 0.2) & ((.66 ; .88 ; 1) ; 0.6 ; 0.2 ; 0.2) \\
((.62 ; .89 ; .91) ; 0.6 ; 0.3 ; 0.5) & ((.44 ; .59 ; .72) ; 0.7 ; 0.2 ; 0.3) & ((.75 ; .79 ; .85) ; 0.8 ; 0.5 ; 0.4) \\
((.62 ; .89 ; .91) ; 0.6 ; 0.3 ; 0.5) & ((.44 ; .59 ; .72) ; 0.7 ; 0.2 ; 0.3) & ((.66 ; .88 ; 1) ; 0.6 ; 0.2 ; 0.2) \\
((.53 ; .73 ; .87) ; 0.7 ; 0.2 ; 0.8) & ((.44 ; .59 ; .72) ; 0.7 ; 0.2 ; 0.3) & ((.65 ; .69 ; .85) ; 0.6 ; 0.8 ; 0.1) \\
((.63 ; .75 ; .89) ; 0.7 ; 0.4 ; 0.6) & ((.47 ; .69 ; .85) ; 0.7 ; 0.2 ; 0.6) & ((.66 ; .88 ; 1) ; 0.6 ; 0.2 ; 0.2) \\
((.62 ; .76 ; .82) ; 0.4 ; 0.1 ; 0.3) & ((.55 ; .62 ; .73) ; 0.8 ; 0.1 ; 0.2) & ((.75 ; .79 ; .85) ; 0.8 ; 0.5 ; 0.4) \\
((.44 ; .59 ; .72) ; 0.7 ; 0.2 ; 0.3) & ((.53 ; .67 ; .99) ; 0.3 ; 0.5 ; 0.2) & ((.65 ; .69 ; .85) ; 0.6 ; 0.8 ; 0.1)
\end{array}\right)
$$

Compute $\mathrm{U}=\left[\mathrm{u}_{\mathrm{ij}}\right]_{8 * 3}$ of $\mathrm{R}$ where. $\mathrm{u}_{\mathrm{ijj}} \omega_{8} \mathrm{r}_{\mathrm{ij}}\left(\mathrm{i} \in \mathrm{I}_{8}\right.$ for quality criteria, $\mathrm{j} \in \mathrm{I}_{3}$ the three IS ) and $\omega=(.25, .25, .30, .20, .25, .20, .20$, and .15$)$.

$$
\mathrm{U}=\left(\begin{array}{cccc}
\mathrm{q}_{1} & \mathrm{q}_{2} & \\
((.155 ; .222 ; .227) ; 0.6 ; 0.3 ; 0.5) & ((.117 ; .172 ; .212) ; 0.7 ; 0.2 ; 0.6) & ((.157 ; .187 ; .222) ; 0.7 ; 0.4 ; 0.6) \\
((.157 ; .187 ; .222) ; 0.7 ; 0.4 ; 0.6) & ((.115 ; .137 ; .215) ; 0.4 ; 0.7 ; 0.2) & ((.165 ; .220 ; .250 ; 0.6 ; 0.2 ; 0.2) \\
((.186 ; .287 ; .273) ; 0.6 ; 0.3 ; 0.5) & ((.132 ; .177 ; .216) ; 0.7 ; 0.2 ; 0.3) & ((.225 ; .237 ; .255) ; 0.8 ; 0.5 ; 0.4) \\
((.124 ; .178 ; .182) ; 0.6 ; 0.3 ; 0.5) & ((.088 ; .118 ; .144) ; 0.7 ; 0.2 ; 0.3) & ((.132 ; .176 ; .250 ; 0.6 ; 0.2 ; 0.2) \\
((.132 ; .182 ; .217) ; 0.7 ; 0.2 ; 0.8) & ((.110 ; .147 ; .180) ; 0.7 ; 0.2 ; 0.3) & ((.162 ; .172 ; .212) ; 0.6 ; 0.8 ; 0.1) \\
((.126 ; .150 ; .178) ; 0.7 ; 0.4 ; 0.6) & ((.094 ; .138 ; .170) ; 0.7 ; 0.2 ; 0.6) & ((.132 ; .176 ; .250 ; 0.6 ; 0.2 ; 0.2) \\
((.124 ; .152 ; .164) ; 0.4 ; 0.1 ; 0.3) & ((.110 ; .124 ; .146) ; 0.8 ; 0.1 ; 0.2) & ((.150 ; .158 ; .170 ; 0.8 ; 0.5 ; 0.4) \\
((.066 ; .088 ; .108) ; 0.7 ; 0.2 ; 0.3) & ((.079 ; .100 ; .148) ; 0.3 ; 0.5 ; 0.2) & ((.097 ; .103 ; .127) ; 0.6 ; 0.8 ; 0.1)
\end{array}\right)
$$


Calculate the comprehensive values $S_{j}$ as: $S_{j}=\sum_{i=1}^{Q} \quad u_{i j} \quad\left(j \in I_{3}\right)$

$\mathrm{S}_{1}=((1.07 ; 1.446 ; 1.571) ; 0.4 ; 0.4 ; 0.8)$

$\mathrm{S}_{2}=((.845 ; 1.113 ; 1.431) ; 0.3 ; 0.7 ; 0.6)$

$\mathrm{S}_{3}=((1.22 ; 1.429 ; 1.736) ; 0.6 ; 0.8 ; 0.6)$

Phase III: Evaluate and Rank the Quality of IS

This phase introduces two types of evaluating and ranking methods as the follows:

(1) Weighted value and ambiguity method

Firstly, calculate the value and ambiguity of truth-membership-membership degree, and indeterminacymembership, and falsity-membership degree for each comprehensive value

$$
\begin{array}{lll}
\mathrm{V}_{\mu}\left(\mathrm{S}_{1}\right)=1.404(.4)^{2}=.224 ; & \mathrm{V}_{v}\left(\mathrm{~S}_{1}\right)=1.404(1-.4)^{2}=.505 ; & \mathrm{V}_{\lambda}\left(\mathrm{S}_{1}\right)=1.404(1-.8)^{2}=.056 \\
\mathrm{~V}_{\mu}\left(\mathrm{S}_{2}\right)=1.121(.3)^{2}=.100 ; & \mathrm{V}_{\mathrm{v}}\left(\mathrm{S}_{2}\right)=1.121(1-.7)^{2}=.100 ; & \mathrm{V}_{\lambda}\left(\mathrm{S}_{2}\right)=1.121(1-.6)^{2}=.179 \\
\mathrm{~V}_{\mu}\left(\mathrm{S}_{3}\right)=1.445(.6)^{2}=.520 ; & \mathrm{V}_{v}\left(\mathrm{~S}_{3}\right)=1.445(1-.8)^{2}=.057 ; & \mathrm{V}_{\lambda}\left(\mathrm{S}_{3}\right)=1.445(1-.6)^{2}=.231
\end{array}
$$

Secondly, calculate the weighted values ( $\theta$-weighted value) for each IS as the follows:

$$
\begin{aligned}
\mathrm{V}_{\theta}\left(\mathrm{S}_{1}\right) & =.224 \theta+.505(1-\theta)+.056(1-\theta) \\
\mathrm{V}_{\theta}\left(\mathrm{S}_{2}\right) & =.100 \theta+.100(1-\theta)+.179(1-\theta) \\
\mathrm{V}_{\theta}\left(\mathrm{S}_{3}\right) & =.520 \theta+.057(1-\theta)+.231(1-\theta)
\end{aligned}
$$

Thirdly, graphically represents weighted values for evaluating and ranking quality of IS. The following figure represents the weighted values of the $S_{1}, S_{2}$ and $S_{3}$

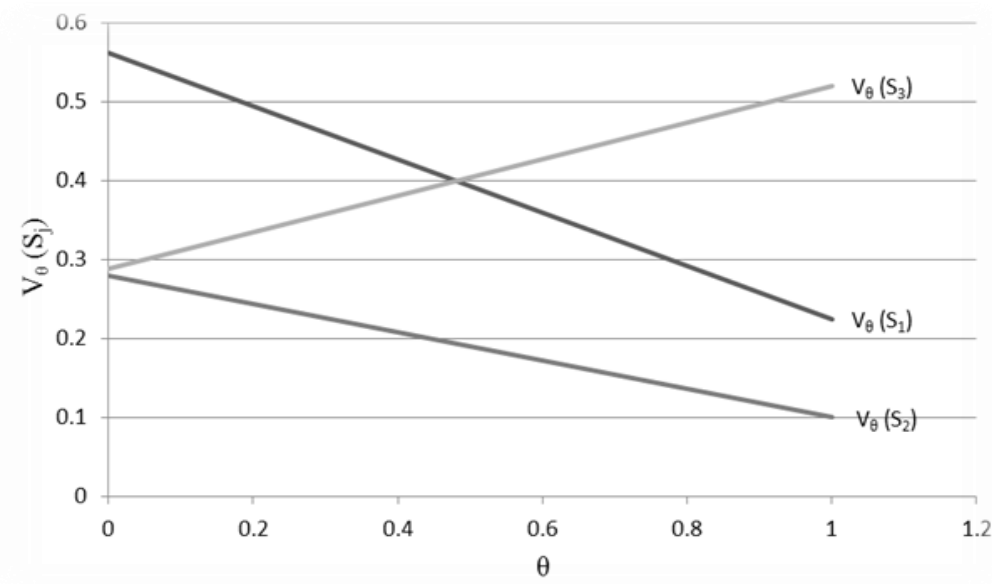

Fig.1. The weighted values of the $S_{1}, S_{2}$ and $S_{3}$

(i) From figure (1), the weighted values of $S_{1}$ and $S_{3}$ have equal values at $\theta=.479$. The weighted ambiguities of $S_{1}$ and $S_{3}$ can be calculated based on Eq. (25) as follows: 
$\mathrm{A}_{.479}\left(\mathrm{~S}_{1}\right)=(1.571-1.070) / 6[.479(.4)+.479(1-.4)+.479(1-.8)]=.047$

$\mathrm{A}_{.479}\left(\mathrm{~S}_{3}\right)=(1.736-1.220) / 6[479(.6)+.479(1-.8)+.479(1-.6)]=.049$

Therefore, $\mathrm{S} 3>\mathrm{S} 1$. Consequently, the quality of the third information system $\left(\mathrm{q}_{3}\right)$ is greater than the quality of the first information system $\left(\mathrm{q}_{1}\right)$.

(ii) From figure (1) for any $\theta \in[0, .479]$ the weighted values of the $S_{1}, S_{2}$ and $S_{3}$ can ranked as the follows: $\mathrm{V}_{\theta}\left(\mathrm{S}_{1}\right)>\mathrm{V}_{\theta}\left(\mathrm{S}_{3}\right)>\mathrm{V}_{\theta}\left(\mathrm{S}_{2}\right)$. Consequently, the quality of the first information system $\left(\mathrm{q}_{1}\right)>$ the quality of the third information system $\left(\mathrm{q}_{3}\right)>$ the quality of the second information system $\left(\mathrm{q}_{2}\right)$

(iii) From figure (1) for any $\theta \in[479,1]$ the weighted values of the $S_{1}, S_{2}$ and $S_{3}$ can ranked as the follows: $\mathrm{V}_{\theta}\left(\mathrm{S}_{3}\right)>\mathrm{V}_{\theta}\left(\mathrm{S}_{1}\right)>\mathrm{V}_{\theta}\left(\mathrm{S}_{2}\right)$. Consequently, the quality of the third information system $\left(\mathrm{q}_{3}\right)>$ the quality of the first information system $\left(\mathrm{q}_{1}\right)>$ the quality of the second information system $\left(\mathrm{q}_{2}\right)$

This method gives more attention to uncertainty in decision making as well as it take into account cut sets of SVTrN numbers that can reflect the information on membership degrees and non-membership degrees. However, the calculations and graphically representation of this method become complex when alternatives increase.

\section{(2) Score and Accuracy Based Method}

$$
\begin{aligned}
& \mathrm{S}\left(\mathrm{S}_{1}\right)=1 / 16[(1.07+2 * 1.446+1.571)(2+.4-.4-.8)]=.414 \\
& \mathrm{~S}\left(\mathrm{~S}_{2}\right)=1 / 16[(.845+2 * 1.113+1.431)(2+.3-.7-.6)]=.281 \\
& \mathrm{~S}\left(\mathrm{~S}_{3}\right)=1 / 16[(1.220+2 * 1.429+1.736)(2+.6-.8-.6)]=.436
\end{aligned}
$$

The results indicated that the ranking order of scores is $S\left(S_{3}\right)>S\left(S_{1}\right)>S(S 2)$ which give the same ordering results as the weighted value and ambiguity based method for any $\theta \in[.479,1]$. Therefore, the quality of the third IS $\left(\mathrm{q}_{3}\right)>$ the quality of the first IS $\left(\mathrm{q}_{1}\right)>$ the quality of the second IS $\left(\mathrm{q}_{2}\right)$. This method provides a simple and flexible method for ranking SVTrN- numbers. However, it does not give more attention to uncertainty in decision making as weighted values and ambiguities based method as well as it does not take into account cut sets of SVTrN numbers that can reflect the information on membership degrees and non-membership degrees.

\section{Conclusion and Future Work}

This work intended to introduce an ISQ evaluation model based on SVTrN- numbers with introducing weighted value and ambiguity based method and score and accuracy based method for evaluating and ranking ISQ. The results indicated that the proposed model can handle ill- known quantities in evaluating ISQ. Also, by analyzing and comparing results of ranking methods, the results indicated that each ranking method has its own advantage that make the proposed model introduces more than one option for evaluating and ranking ISQ. In this perspective, the weighted value and ambiguity based method gives more attention to uncertainty in decision making as well as it take into account cut sets of SVTrN numbers that can reflect the information on membership degrees and non-membership degrees. Also, by adapting the score and accuracy based method for SVTrN- numbers, the results indicated that this method provides a simple and flexible method for ranking SVTrN- numbers. However, it does not give more attention to uncertainty in decision making as weighted values and ambiguities based method.

For future work, SVTrN-numbers can be applied widely for more real practical applications with adapting and generalizing existing methods of ranking fuzzy numbers and intuitionistic fuzzy number to give more efficient results. 


\section{References}

[1] Al-Qutaish, R. An Investigation of the Weaknesses of the ISO 9126 International Standard. 2nd Int. Con. Comput. Elect. Eng. IEEE. 2009.

[2] Atanassov. K. T. Intuitionistic fuzzy sets. Pysica-Verlag A Springer-Verlag Company. New York. 1999.

[3] Atanassov, K. Intuitionistic fuzzy sets. Fuzz. Set. Syst. 1986, 20, 87-96.

[4] Chen, J., Ye, J. Some Single-Valued Neutrosophic Dombi Weighted Aggregation Operators for Multiple Attribute Decision-Making. Symmetry. MDPI. 2017, 9(6).

[5] De, K. P., Das, D. A Study on Ranking of Trapezoidal Intuitionistic Fuzzy Numbers. Int. J. Comput. Inform. Syst. \& Indu. Mana. Applic. 2014, 6, 437-444.

[6] Deli, I., Şubaş, Y. A ranking method of single valued neutrosophic numbers and its applications to multiattribute decision making problems. Int. J. Mach. Learn. \& Cyber. 2016.

[7] Deli, I., Subas, Y. Single valued neutrosophic numbers and their applications to multi-criteria decision making problem. Neutro. Set. Syst. 2014, 2(1), 1-13.

[8] Durgesh, S., Su-Hua, W., Dengjie, C. Quality Models: Role and Value in Software Engineering. 2nd Int. Con. Soft. Tech. \& Eng. (ICSTE). 2010, 320-324.

[9] International Organization for Standardization. ISO/IEC 9126-1- Software engineering - product qualitypart 1 Quality model. ISO/IEC. 2001.

[10] International Organization for Standardization. ISO/IEC 25030 - Software engineering-Software product Quality Requirements and Evaluation (SQuaRE)-Quality requirements. ISO/IEC. 2007.

[11] International Organization for Standardization. ISO/IEC-25012 - Software engineering - Software product Quality Requirements and Evaluation (SQuaRE) - Data quality model. 2008.

[12] International Organization for Standardization. ISO/IEC 25010 - Systems and software engineering Systems and software Quality Requirements and Evaluation (SQuaRE) - System and software quality models. ISO/IEC. 2011.

[13] Li, D. A ratio ranking method of triangular intuitionistic fuzzy numbers and its application to MADM problems. Comput. \& Math. Applic. 2010, 60, 1557-1570.

[14] Li, D., Nan, J., Zhang, M. A ranking method of triangular intuitionistic fuzzy numbers and application to decision making. Int. J. Comput. Intell. Syst. 2010, 3(5), 522-530.

[15] Liang, C., Zhao, S., Zhang, J. Aggregation operators on triangular intuitionistic fuzzy numbers and its application to multi-criteria decision making problems. Found. Comput. \& Deci. Sci. 2014, 39.

[16] Liu, P., Zhang, X. Some maclaurin symmetric mean operators for single-valued trapezoidal neutrosophic numbers and their applications to group decision making, international journal of fuzzy system. Int. J. Fuzz. Syst. 2017.

[17] Miguel, J., Mauricio, D., Rodríguez, G. A Review of Software Quality Models for the Evaluation of Software Products. Int. J. Soft. Eng. \& Applic. (IJSEA). 2014, 5(6).

[18] Mitchell, B. Ranking - Intuitionistic Fuzzy numbers. Int. J. Uncert. Fuzz. Knowl. Bas. Syst. 2004, 12, 377-386.

[19] Oriol, M., Marco, J., Franch, X. Quality models for web services. A syst. map. Inform. \& Soft. Tech. 2014, 56, 1167-1182.

[20] Peng, J., Wang, J., Wu, X., Wang, J., Chen, X. Multivalued neutrosophic sets and power aggregation operators with their applications in multi-criteria group decision-making problems. Int. J. Comput. Intell. Syst. 2014, 8(2), 345-363.

[21] Prakash, K., Suresh, M., Vengataasalam, S. A new approach for ranking of intuitionistic fuzzy numbers using a centroid concept. Math Sci. 2016, 10, 177-184.

[22] Smarandache, F. Neutrosophic set a generalisation of the intuitionistic fuzzy sets. Int. J. Pure. Applic. 
Math. 2005, 24, 287-297.

[23] Smarandache, F. Neutrosophy: Neutrosophic Probability, Set, and Logic: Analytic Synthesis \& Synthetic Analysis. Ameri. Res. Press: Rehoboth. DE. USA. 1998.

[24] Srivastava, P., Kumar, K. an Approach towards Software Quality Assessment. Springer-Verlag Berlin Heidelberg. 2009, 150-160.

[25] Subas,Y. Neutrosophic numbers and their application to Multi-attribute decision making problems (In Turkish) (Master's Thesis, Kilis 7 Aralık University, Graduate School of Natural and Applied Science). 2015.

[26] Ye, J. Expected value method for intuitionistic trapezoidal fuzzy multicriteria decision-making problems, Int. J. Gen. Syst. 2011, 38, 11730-11734.

[27] Ye, J. Multi criteria decision-making method using the correlation coefficient under single-value neutrosophic environment. Int. J. Gen. Syst. 2013, 42, 386-394.

[28] Ye, J. A multi criteria decision-making method using aggregation operators for simplified neutrosophic sets. J. Intell. Fuzz. Syst. 2014, 26, 2459-2466.

[29] Ye, J. Trapezoidal neutrosophic set and its application to multiple attribute decision-making. Neural. Comput \& Applic. 2015, 26, 1157-1166.

[30] $\mathrm{Yu}, \mathrm{D}$. Intuitionistic trapezoidal fuzzy information aggregation methods and their applications to teaching quality evaluation. J. Inform. \& Comput. Sci. 2013, 10(6), 1861-1869.

[31] Yavari, A., Golbaghi, M., Momeni, H. Assessment of Effective Risk in Software Projects based on Wallace's Classification Using Fuzzy Logic. I.J. Information Engineering and Electronic Business, 2013, 4, 58-64

[32] SalamaA., Broumi S., Smarandache F. Neutrosophic Crisp Open Set and Neutrosophic Crisp Continuity via Neutrosophic Crisp Ideals. I.J. Information Engineering and Electronic Business, 2014, 3, 1-8

[33] Salama A., Broumi S., Alblowi S. Introduction to Neutrosophic Topological Spatial Region, Possible Application to GIS Topological Rules. I.J. Information Engineering and Electronic Business, 2014, 6, 1521

\section{Authors' Profiles}

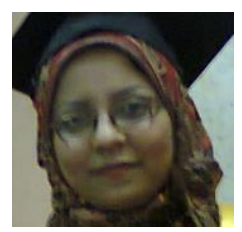

Samah Ibrahim Abdel Aal is an assistant lecturer at information systems department, College of Computers and Informatics, Zagazig University where graduated and is now a Ph.D., Egypt. She is teaching several courses for information systems management, expert systems, quality management and information systems analysis and design.

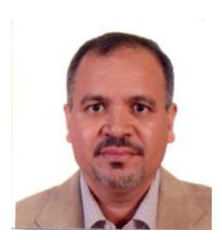

Mahmoud M. A. Abd Ellatif is associate professor of Information Systems and Vice Dean for Postgraduate \& Researches at Faculty of Computers \& Information, Helwan University, Egypt. , Co-professor, University of Jeddah, KSA His researches focus on how to use data mining techniques and semantic web technologies to apply the framework of PIECES in Software Engineering. 


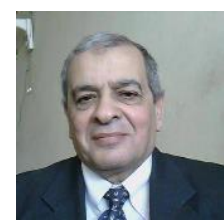

Mohamed Monir Hassan is a Head of Information Systems Department at College of Computers and Informatics, Zagazig University, Egypt. He has published several researches that examine topics related to information security and information systems development. Mohamed is teaching several courses for information systems, database, information security, and data mining.

How to cite this paper: Samah Ibrahim Abdel Aal, Mahmoud M. A. Abd Ellatif, Mohamed Monir Hassan,"Proposed Model for Evaluating Information Systems Quality Based on Single Valued Triangular Neutrosophic Numbers", International Journal of Mathematical Sciences and Computing(IJMSC), Vol.4, No.1, pp.1-14, 2018.DOI: 10.5815/ijmsc.2018.01.01 